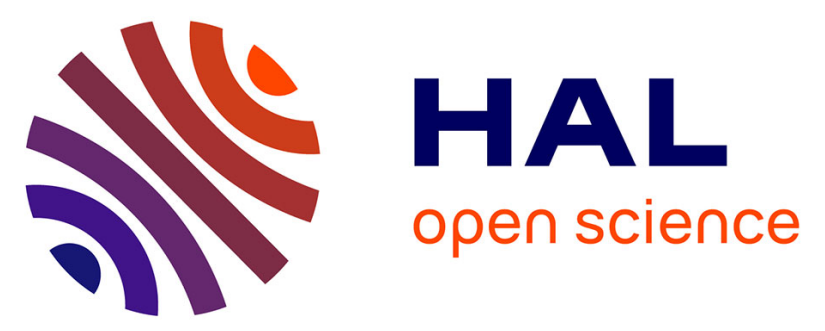

\title{
Rodízio de postos de trabalho como exigência legal: análise da aceitação e percepção de trabalhadores do abate de bovinos
}

Iracimara de Anchieta Messias, Adelaide Nascimento, Raoni Rocha

\section{- To cite this version:}

Iracimara de Anchieta Messias, Adelaide Nascimento, Raoni Rocha. Rodízio de postos de trabalho como exigência legal: análise da aceitação e percepção de trabalhadores do abate de bovinos. 2021. hal-03223862

\section{HAL Id: hal-03223862 \\ https://hal-cnam.archives-ouvertes.fr/hal-03223862}

Preprint submitted on 11 May 2021

HAL is a multi-disciplinary open access archive for the deposit and dissemination of scientific research documents, whether they are published or not. The documents may come from teaching and research institutions in France or abroad, or from public or private research centers.
L'archive ouverte pluridisciplinaire HAL, est destinée au dépôt et à la diffusion de documents scientifiques de niveau recherche, publiés ou non, émanant des établissements d'enseignement et de recherche français ou étrangers, des laboratoires publics ou privés.

\section{(c)(1)}

Distributed under a Creative Commons Attribution| 4.0 International License 


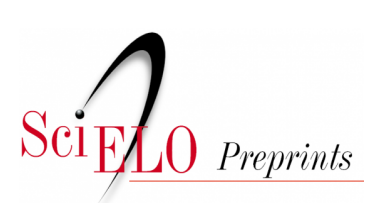

Situação: O preprint não foi submetido para publicação

\section{Rodízio de postos de trabalho como exigência legal: análise da aceitação e percepção de trabalhadores do abate de bovinos} Iracimara de Anchieta Messias, Adelaide Nascimento, Raoni Rocha

https://doi.org/10.1590/SciELOPreprints.2168

Este preprint foi submetido sob as seguintes condições:

- Os autores declaram que estão cientes que são os únicos responsáveis pelo conteúdo do preprint e que o depósito no SciELO Preprints não significa nenhum compromisso de parte do SciELO, exceto sua preservação e disseminação.

- Os autores declaram que os necessários Termos de Consentimento Livre e Esclarecido de participantes ou pacientes na pesquisa foram obtidos e estão descritos no manuscrito, quando aplicável.

- Os autores declaram que a elaboração do manuscrito seguiu as normas éticas de comunicação científica.

- Os autores declaram que os dados, aplicativos e outros conteúdos subjacentes ao manuscrito estão referenciados.

- O manuscrito depositado está no formato PDF.

- Os autores declaram que a pesquisa que deu origem ao manuscrito seguiu as boas práticas éticas e que as necessárias aprovações de comitês de ética de pesquisa, quando aplicável, estão descritas no manuscrito.

- Os autores concordam que caso o manuscrito venha a ser aceito e postado no servidor SciELO Preprints, a retirada do mesmo se dará mediante retratação.

- Os autores concordam que o manuscrito aprovado será disponibilizado sob licença Creative Commons CCBY.

- O autor submissor declara que as contribuições de todos os autores e declaração de conflito de interesses estão incluídas de maneira explícita e em seções específicas do manuscrito.

- Os autores declaram que o manuscrito não foi depositado e/ou disponibilizado previamente em outro servidor de preprints ou publicado em um periódico.

- Caso o manuscrito esteja em processo de avaliação ou sendo preparado para publicação mas ainda não publicado por um periódico, os autores declaram que receberam autorização do periódico para realizar este depósito.

- O autor submissor declara que todos os autores do manuscrito concordam com a submissão ao SciELO Preprints.

Submetido em (AAAA-MM-DD): 2021-04-25

Postado em (AAAA-MM-DD): 2021-04-28 


\section{Rodízio de postos de trabalho como exigência legal: análise da aceitação e percepção de trabalhadores do abate de bovinos}

\section{Job rotation as a legal requirement: analysis of the acceptance and perception of bovin slaughter workers}

Iracimara de Anchieta Messias - (https://orcid.org/0000-0003-2578-384) ${ }^{1}$

Adelaide Nascimento - (https://orcid.org/0000-0002-4847-8762) ${ }^{2}$

Raoni Rocha - (https://orcid.org/0000-0003-1181-0132) ${ }^{3}$

${ }^{1}$ Núcleo de Estudos e Pesquisas em Ergonomia - NEPErg / Faculdade de Ciências e Tecnologia da Universidade Estadual Paulista - FCT/UNESP - campus de Presidente Prudente/SP

${ }^{2}$ Conservatoire national des arts et métiers - Paris/França

${ }^{3}$ Departamento de Engenharia de Produção, Administração e Economia Universidade Federal de Ouro Preto

Correspondência: Iracimara de Anchieta Messias - Faculdade de Ciências e Tecnologia/UNESP - Departamento de Planejamento, Urbanismo e Ambiente

Rua Roberto Simonsen, 305 - Centro Educacional -Presidente Prudente/SP - CEP: 19060-900.

e-mail: iracimara.messias@unesp.br

Resumo: Este artigo apresenta experiência de abordagem participativa preliminar à implantação da NR-36, que regula o trabalho em empresas produtoras de carne e derivados. Apesar de a normativa prever a participação do trabalhador nos processos de implantação de rodízio de postos, não esclarece como fazê-lo. O estudo foi desenvolvido no setor de abate de bovinos utilizando dois métodos complementares entre si: observações do trabalho in loco, para seleção dos postos prioritariamente elegíveis ao rodízio, e levantamento da percepção argumentada dos trabalhadores sobre o nível de aceitação de realização do rodízio nos postos selecionados. A princípio, $72 \%$ dos trabalhadores não aceitavam realizar o rodízio. Após inclusão e participação no processo de implantação, $86 \%$ dos trabalhadores da área suja e 64\% da área limpa 
concordaram em realizar. Como evidências das vantagens em realizar rodízio, a variabilidade no trabalho (30\%), aprendizado e ganho de experiência (40\%), mudanças de movimentos (35\%) e descanso físico (32\%) se destacam. Como desvantagens, sobressaem o medo de acidentes (30\%) e o medo da mudança e do desconhecido (25\%). Concluímos que a abordagem participativa preliminar às mudanças de desenhos organizacionais contribui na compreensão e percepção dos trabalhadores sobre as vantagens e desvantagens do rodízio, indicando melhoria dos processos no cumprimento das exigências legais.

Palavras-chave: Participação, Rotação, Matadouro, Percepção, Trabalho.

Abstract: This article presents an experience of a participative approach preliminary to the implementation of NR-36, which regulates work in meat and meat products companies. Although the norms provide for worker participation in the processes of implementing job rotation, they do not explain how to do it. The study was developed in the beef slaughtering sector using two complementary methods: observation of the work in loco, in order to select the jobs that are primarily eligible for the rotation, and a survey of the workers' perception of the level of acceptance of the rotation in the selected jobs. At first, $72 \%$ of the workers did not accept the rotation. After inclusion and participation in the implementation process, $86 \%$ of the workers in the dirty area and $64 \%$ in the clean area agreed to the rotation. As evidence of the advantages of the rotation, the variability in the work (30\%), learning and gain of experience (40\%), changes in movements (35\%), and physical rest (32\%) stand out. As disadvantages, the fear of accidents (30\%) and the fear of change and of the unknown (25\%) stand out. We conclude that the participatory approach preliminary to the changes in organizational design contributes to the understanding and perception of workers about the advantages and disadvantages of the rotation, indicating improvement of processes in compliance with legal requirements.

Keywords: Participation, Rotation, Slaughterhouse, Perception, Work 


\section{Introdução}

O trabalho em linha de produção corresponde a uma organização na qual o trabalhador deve realizar as suas tarefas a um ritmo determinado pelas máquinas. Caracteriza-se também pela realização repetitiva de uma tarefa sobre um produto em movimento perpétuo ${ }^{1}$. Este tipo de organização do trabalho envolve várias exigências psicossociais e biomecânicas (repetição de gestos, ritmo elevado, concentração de força a ser aplicada, posturas incômodas e micropausas insuficientes) que podem aumentar o risco de doenças osteomusculares relacionadas ao trabalho (DORT) ${ }^{2,3,4,5}$. O rodízio de postos de trabalho aparece geralmente nesse contexto como uma das soluções visando reduzir os riscos de DORT.

No setor dos frigoríficos brasileiros, o rodízio de postos de trabalho tornou-se uma exigência legal a partir da Norma Regulamentadora (NR) 36 - Segurança e Saúde no Trabalho em Empresas de Abate e Processamento de Carnes e Derivados ${ }^{6}$, publicada em 19 de abril de 2013. Essa NR tem como base de sua criação registros de inspeções realizadas por Auditores Fiscais do Trabalho, denúncias de sindicatos, avanços científicos e pressão política, entre outros ${ }^{7}$. Em seu texto, a NR 36 enumera 15 itens principais, que vão desde mobiliário e postos de trabalho, até informações e treinamentos em saúde e segurança no trabalho, estabelecendo os requisitos mínimos para avaliar, controlar e monitorar os riscos (biológicos, físicos, químicos, de acidentes, ergonômico) na atividade ${ }^{6}$. Estes riscos geram transtornos no estado de saúde dos trabalhadores, dado que os processos de produção em frigoríficos/matadouros são organizados de tal maneira que a probabilidade de agravos a saúde é bastante alta ${ }^{8}$.

Assim, um dos princípios da NR-36 é reduzir a exposição aos riscos "através de alternância de atividades, entre tarefas com cadência estabelecida por máquinas, esteiras e nórias, e outras tarefas em que o trabalhador possa determinar livremente o ritmo de trabalho" (NR-36, 3.14.7.11) ${ }^{6}$.

Segundo Ouellet ${ }^{9}$, o rodízio de postos é uma prática frequente no setor de frigoríficos, pois é percebido como uma maneira de aumentar a polivalência dos trabalhadores e reduzir as DORT. O estudo de Fardelau \& Vézina ${ }^{2}$, por exemplo, mostra que tanto os encarregados quanto os trabalhadores são favoráveis ao rodízio de postos em um frigorífico de abate e processamento de porcos. Uma intervenção 
ergonômica realizada por Barth e Guimarães ${ }^{10}$, indica que os trabalhadores de um frigorífico de aves relatam menos dores e desconfortos após a implementação do rodízio de postos. Por outro lado, alguns estudos demonstram que os efeitos alcançados com a implementação do rodízio são geralmente inferiores ao esperado e que o rodízio sozinho não seria a solução para as DORT ${ }^{11}, 12,13,14$. Na realidade, as condições nas quais se realiza a implementação do rodízio são determinantes para o seu sucesso ou fracasso. ${ }^{2}$.

No Brasil, apesar da publicação da NR 36 ter sido um marco regulatório importante para o setor de frigorífico, observamos que sem a análise participativa e o conhecimento dos determinantes reais na realização do trabalho, a referida norma pode não passar de mais um marco estritamente regulatório ${ }^{15}$.

Uma recente revisão bibliográfica ${ }^{16}$ destaca a eficácia de uma abordagem participativa em contextos de prevenção de DORT, confirmando achados no setor de frigoríficos no Brasil ${ }^{15}$. Através de uma pesquisa empírica utilizando as técnicas de focus group e de confrontação coletiva, Nascimento \& Messias ${ }^{17}$ evidenciaram dimensões a serem consideradas no desenho de rodízios de postos de trabalho em abates de bovinos. Além do trabalho coletivo, essas dimensões compreendem as competências, o ritmo de trabalho e as fontes de prescrição contraditórias.

No contexto acima, o objetivo do presente artigo é apresentar uma compreensão da aceitação e da percepção dos trabalhadores quanto às barreiras (ou dificultadores) e aos facilitadores do rodízio de postos exigido pela NR-36. O estudo utilizou dois métodos complementares: observações do trabalho real para seleção dos postos prioritariamente elegíveis ao rodízio; e o levantamento, por meio de questionário semiestruturado, visando investigar a percepção argumentada dos trabalhadores acerca das vantagens e desvantagens do rodízio, bem como o seu nível de aceitação, de maneira geral e específica aos postos selecionados. Desta forma, este artigo se inscreve na perspectiva de uma abordagem participativa preliminar ao desenho do rodízio de postos de trabalho em frigoríficos, baseada na ergonomia da atividade. Em geral, abordagem participativa é evidente na intervenção ergonômica ${ }^{18}$, entretanto não é definida uma prática padrão de como ela pode ocorrer, pois isso depende do contexto e dos objetivos de cada intervenção ${ }^{19}$. O desafio é mostrar a importância da atividade e sua elucidação por parte dos trabalhadores para conceber a organização não somente sob o seu prisma estrutural, como fazem os organizadores, mas também através de 
múltiplas interações entre os diferentes trabalhadores da organização. Uma abordagem preliminar à implementação de rodízios nos parece, dessa forma, fundamental para melhoria das condições de trabalho e redução dos riscos de DORT.

\section{Métodos}

\subsection{Contexto e população}

A indústria estudada trata-se de empresa familiar, em funcionamento nos últimos 20 anos, utilizando a estrutura física de outro frigorífico anteriormente existente no local. Adequações foram realizadas atendendo normativas internacionais, tanto na concepção de sua estrutura física, quanto no atendimento a diversos quesitos de produção de carne exigidos internacionalmente, já que o objetivo foi, desde o início, atender exclusivamente o mercado externo, ou seja, trata-se de uma produção tipo exportação.

$\mathrm{Na}$ empresa trabalham, aproximadamente, 600 indivíduos, sendo 70\% na produção e 30\% no administrativo. A área operacional e de produção é dividida em 13 setores, sendo o setor de abate, objeto desse estudo, o local onde se inicia o ciclo de trabalho com o abate dos bovinos. Neste setor, os trabalhadores são considerados experientes, por desempenharem atividades que exigem competências e habilidades específicas. Nos outros setores operacionais, a rotatividade é grande e os trabalhadores não necessitam de conhecimento prévio para realização de suas atividades.

O setor de abate de bovinos é composto por 104 trabalhadores, sendo 91\% de homens com idade entre 40 a 54 anos. São cinco as funções exercidas, sendo elas: magarefe (responsável pela retirada do couro do gado), faqueiro (responsável pelo corte e redução de peças grandes), finalizador (responsável por eliminar restos e excessos na peça), auxiliar de produção (trabalho geral sem usar a faca) e serrador (responsável pelo corte de peças grandes com serra pneumática). O trabalho ocorre em um único turno com jornada diária de oito horas, que pode ser aumentada por horas extras de trabalho quando do aumento da demanda. A produção inicia-se com a chegada do boi vivo. Em seguida, eles permanecem no mínimo um dia em confinamento com dieta hídrica, seguindo normativas específicas, para em seguida se iniciar os procedimentos de abate. O setor é divido em duas zonas de trabalho, constituindo-se de: (i) área suja, que se inicia no curral com o preparo do boi para o abate, o abate em si e a retirada completa 
do couro; e, (ii) área limpa, onde o boi, já sem pele, passa pela serragem da carcaça, retirada da cabeça, vísceras, lavagem, etiquetagem, pesagem e carimbo das partes cortadas, seguindo para a câmara frigorífica para armazenamento e posterior transporte.

\subsection{Material e métodos}

O dispositivo desenvolvido no projeto inicial do rodízio de postos apresentado neste artigo compreende técnicas de observação do trabalho real e entrevistas semiestruturadas a partir de um instrumento adaptado de Ouellet \& Vézina (2003)

Após uma fase preliminar de observações livres, outra fase de observações sistemáticas do trabalho real foi realizada em 8 postos de trabalho considerados de risco elevado para o desenvolvimento de DORT, tanto pelos aspectos repetitivos dos gestos e uso de maquinário do tipo serra pneumática, quanto pelo trabalho em plataformas e em presença de fatores de riscos psicossociais ${ }^{17}$. Os postos selecionados na área suja foram os seguintes: Sangria (onde é cortada a artéria aorta do boi para retirada de seu sangue); Etiqueta e Transpasse (local em que o bovino abatido recebe etiqueta de identificação e é realizada a mudança de lado onde estão sendo realizados os cortes); Tira-couro (posto onde ocorre a esfola mecânica com a qual é retirado o couro do animal), e Serra Peito (onde inicia-se a separação pelo meio do animal, sendo utilizada serra pneumática). Já os postos selecionados na área limpa foram: Serra Carcaça (serragem do animal ao meio com serra pneumática), Limpeza da Bacia (evisceração da região interna da parte pélvica do animal); Barrigada (evisceração da região abdominal do animal); e Carimbo (onde é registrado e carimbado na carcaça do boi, autenticando suas condições sanitárias e suas características como peso e origem).

Esses postos foram submetidos à análise através do instrumento adaptado de Ouellet \& Vézina $(2003)^{9}$ utilizado durante entrevistas individuais visando a coleta de dados sobre a aceitação e percepção dos trabalhadores quanto as vantagens e desvantagens do rodízio. Nesta etapa, todos os trabalhadores do setor de abate foram convidados a participar, com a concordância de 80 deles, dentre um total de 104 . Destes, um trabalhador foi dispensado pela empresa, permanecendo um total de 79 trabalhadores no estudo, o que corresponde a $76 \%$ de participação. Foram realizadas entrevistas de aproximadamente 30 minutos com cada trabalhador, de forma individual e voluntária, antes do início da jornada de trabalho. 
O instrumento é dividido em duas partes. A primeira contém questões abertas e fechadas que abordam: (i) identificação do trabalhador; (ii) tempo de trabalho na função e identificação da área de trabalho (suja ou limpa); (iii) se no momento realiza rodízio; (iv) se já realizou rodízio; (v) se concorda ou não que o rodízio é uma boa solução para prevenção de traumas musculoesqueléticos, informando os motivos; (vi) se está disposto a realizar ou não rodízio e por quê. Nas questões abertas, o trabalhador pôde indicar os motivos para aceitar ou não a realização do rodízio de postos, manifestando a sua percepção quanto às vantagens ou desvantagens em realizá-lo, indicando assim os facilitadores e barreiras para implementação do rodízio.

Após a aplicação da primeira parte do instrumento, todos os trabalhadores foram recrutados em pequenos grupos antes do início da jornada de trabalho, para encontros com os pesquisadores onde eram informados sobre o propósito do estudo e assinavam o termo de concordância na participação. Nestes encontros era apresentado o delineamento do estudo sendo explicitadas detalhadamente as etapas a serem desenvolvidas. Junto a isso, eles eram informados da sua participação ativa durante todo o processo de implementação do rodízio. Essa foi a condição para a realização do estudo acordada com os gestores e atendia também prerrogativa da NR-36 (item 36.14.7.2) ${ }^{6}$. Em função das discussões oriundas destes encontros, quando observada uma modificação na verbalização dos trabalhadores em aceitar ou não rodízio de postos, a questão (vi) da etapa anterior, sobre a disposição do trabalhador em participar ou não do rodízio, era novamente aplicada, agora com a segunda parte do instrumento.

A segunda parte do instrumento, representada pela Figura 1, é constituída pela apresentação de quatro postos previamente selecionados para cada uma das áreas (suja e limpa) considerando oito variáveis, as quais possibilitaram ao trabalhador expressar as razões pelas quais aceitaria ou não ocupar os postos apresentados. Nesta figura são apresentadas as subdivisões das colunas, sendo que na primeira coluna à esquerda são apresentados os quatro postos selecionados de cada área, como indicado anteriormente. $\mathrm{Na}$ coluna seguinte, os trabalhadores respondiam se já ocuparam o referido posto e, em seguida, se poderiam ocupá-lo. A partir da quarta coluna o trabalhador indicava os motivos para aceitar ou não os postos, baseados nas seguintes variáveis: força aplicada (se forte ou fraca); cadência (se lenta ou rápida); postura (se confortável ou desconfortável); aprendizado (se fácil ou difícil); pressão e/ou tensão psicológica (se elevada ou baixa); gerenciamento do tempo (se alto ou baixo); e relação com colegas 
(se boa ou ruim). Por último, através de questões abertas, os participantes informavam em qual(is) posto(s) de trabalho eles concordavam em realizar o rodízio, justificando a sua escolha; e em qual(is) posto(s) jamais concordariam em realizar rodízio, também justificando a resposta.

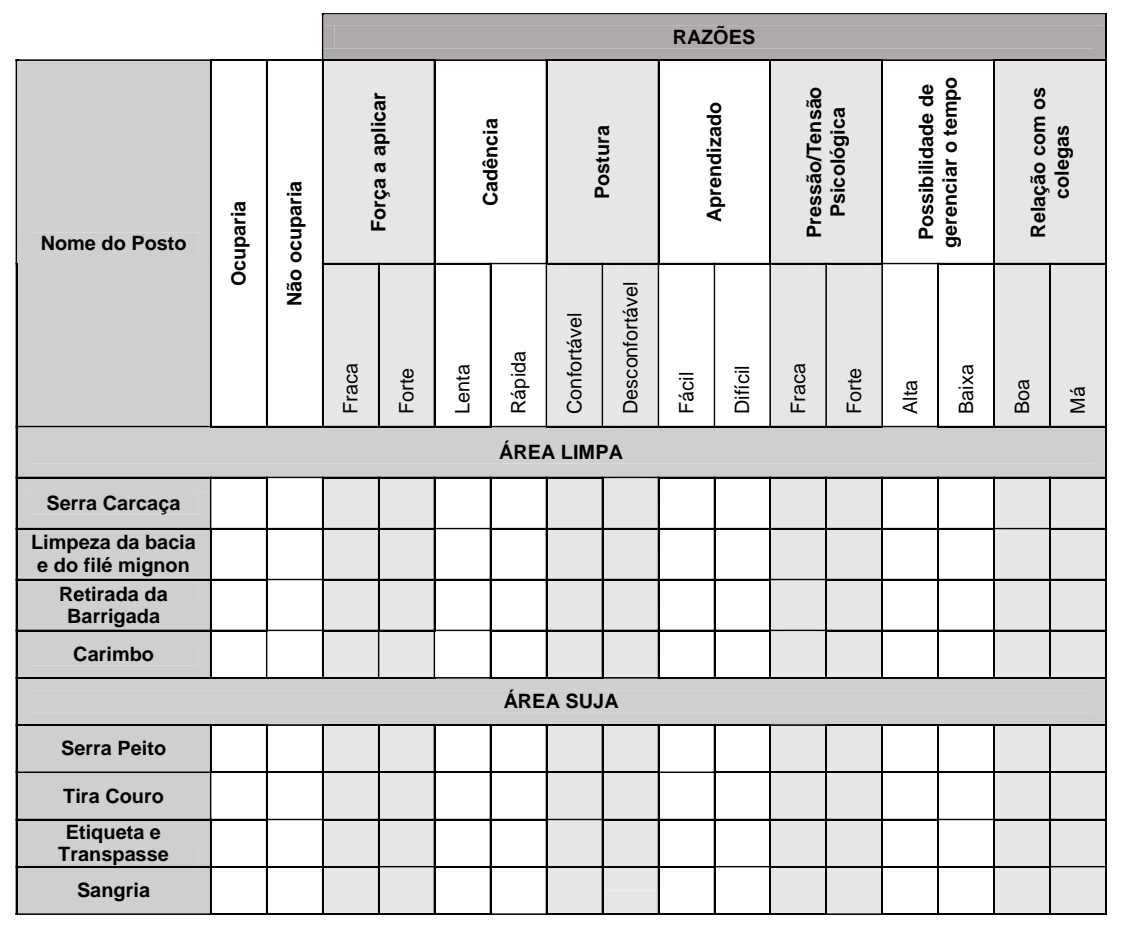

Figura 1- Parte de dispositivo desenvolvido (inspirado no instrumento de Ouellet \& Vézina ${ }^{9}$ ) para conhecimento da aceitação do rodízio de postos previamente selecionados para áreas suja e limpa e razões para aceitar ou não ocupá-los.

Com base nas observações do trabalho real, foram identificados quatro postos nos quais já se realizava o rodízio, porém de maneira não formalizada. Foram coletados dados relativos à percepção dos trabalhadores envolvidos e realizou-se análise da atividade dos postos em questão com a ajuda do software Actograph ${ }^{1}$.

A realização da pesquisa teve aprovação do Comitê de Ética em Pesquisa com Seres Humanos da FCT/UNESP, CAAE no. 24268713.0.0000.5402, de acordo com a resolução nº 196/1996 do Conselho Nacional de Saúde.

\footnotetext{
${ }^{1}$ https://actograph.io/en/
} 


\section{Resultados}

\subsection{Baixa aceitação inicial do rodízio de postos}

Sobre a aceitação do rodízio de postos, $28 \%$ dos entrevistados afirmaram, inicialmente, estarem dispostos a realizá-lo. Destes, 30\% disseram que seria uma boa solução para diminuição dos riscos do trabalho, 30\% relataram que aprenderiam novas atividades e $20 \%$ informaram que teriam alívio para os esforços físicos e repetitivos. Os demais trabalhadores $(72 \%)$ foram contrários à realização do rodízio, sendo apresentados como motivos mais frequentes a insegurança na realização de atividades sem habilidades específicas para desenvolvê-las e a incerteza no treinamento adequado para estar apto a fazê-la (35\%), além de exposição mais frequente a acidentes (30\%).

Observamos que, após os trabalhadores terem conhecimento das etapas do estudo e que teriam garantida a participação durante todo o processo de implementação, $86 \%$ da área suja e 64\% da área limpa mudaram de opinião e disseram estar dispostos a realizar rodízio de postos compreendendo ser essa uma boa solução para prevenção de riscos à saúde.

\subsection{Vantagens e desvantagens do rodízio do ponto de vista do trabalhador}

Na Figura 2 são apresentadas as vantagens e desvantagens mais frequentemente relatadas pelos trabalhadores em realizar o rodízio de postos. A porcentagem, em cada uma das categorias definidas neste quadro, se refere ao grupo de trabalhadores entrevistados que manifestaram verbalmente algum elemento dessa categoria. 


\begin{tabular}{|c|c|}
\hline \multicolumn{2}{|c|}{ ÁREA SUJA (n=42) } \\
\hline Vantagens do rodízio & Desvantagens do rodízio \\
\hline Variabilidade no trabalho ( $30 \%)$ & Medo de acidentes (30\%) \\
\hline $\begin{array}{l}\text { "Porque já sabe o que tem que fazer" } \\
\text { "Não se dificulta" } \\
\text { "Não ficaria sozinho" } \\
\text { "Muda de lugar" } \\
\text { "Porque nao pára o serviço" }\end{array}$ & $\begin{array}{l}\text { "É perigoso colocar pessoas inexperientes" } \\
\text { "Acho que precisa ter o perfil para fazer o que } \\
\text { faço" }\end{array}$ \\
\hline Ascensão no trabalho (28\%) & Medo do desconhecido (25\%) \\
\hline $\begin{array}{l}\text { "Aprende outro serviço" } \\
\text { "Porque aprende outros serviços" } \\
\text { "Aprende outras coisas e é bom para o trabalho" }\end{array}$ & $\begin{array}{l}\text { "Muda o jeito de trabalhar, é ruim..." } \\
\text { "Ruim cada dia fazer uma coisa diferente" } \\
\text { "Já estou acostumado com meu lugar" }\end{array}$ \\
\hline Alívio esforços físicos (22\%) & Sente-se inseguro (18\%) \\
\hline $\begin{array}{l}\text { "Ajuda a descansar" } \\
\text { "Meu serviço é pesado" } \\
\text { "Aqui cansa muito" }\end{array}$ & \multirow[t]{3}{*}{$\begin{array}{l}\text { "Depende do lugar que vai" } \\
\text { "Depende do serviço, um mais é fácil e outro mais } \\
\text { difícil" }\end{array}$} \\
\hline Alívio aos movimentos repetitivos (20\%) & \\
\hline $\begin{array}{l}\text { "Uma terapia, para trabalho muito repetitivo" } \\
\text { "Muda de movimento" }\end{array}$ & \\
\hline \multicolumn{2}{|c|}{ ÁREA LIMPA (n=37) } \\
\hline Vantagens do rodízio & Desvantagens do rodízio \\
\hline Aprendizado e ganho de experiência ( $40 \%)$ & Insegurança (12\%) \\
\hline $\begin{array}{l}\text { "Ganho experiência e melhoro meu trabalho" } \\
\text { "Fico por dentro de tudo que acontece" } \\
\text { "Porque não fica parado em um só lugar" } \\
\text { "Aprendo outra função" } \\
\text { "Aprendo outro serviço" }\end{array}$ & $\begin{array}{l}\text { "Porque não tem lugar certo" } \\
\text { "Acho que se for para outro lugar é pior, porque } \\
\text { os movimentos são piores" }\end{array}$ \\
\hline Mudança de movimentos (35\%) & Penosidade (10\%) \\
\hline $\begin{array}{l}\text { "Porque não fica fazendo coisa repetitiva" } \\
\text { "Tem mudança de movimento" } \\
\text { "Serviço não fica repetitivo" } \\
\text { "Não fica repetitivo o trabalho" } \\
\text { "Exercito outras partes do corpo" }\end{array}$ & \multirow[t]{3}{*}{$\begin{array}{l}\text { "Difícil, muito difícil outro serviço" } \\
\text { "Muito cansativo e pesado" }\end{array}$} \\
\hline Descanço Físico (32\%) & \\
\hline $\begin{array}{l}\text { "Descansa o corpo" } \\
\text { "Ameniza cansaço do trabalho" } \\
\text { "Alívio para as dores" } \\
\text { "O que faço é corrido e cansativo; mudar seria } \\
\text { bom para descansar" }\end{array}$ & \\
\hline
\end{tabular}

Figura 2 - Lista das vantagens e desvantagens do rodízio mais frequentemente citadas por todos os trabalhadores entrevistados no setor do abate para as áreas suja e limpa (Questionário adaptado ${ }^{9}$ ).

A figura nos mostra que os trabalhadores da área suja destacam como vantagens do rodízio a variabilidade no trabalho (30\%), a ascensão profissional (28\%), o alívio de esforços físicos no geral $(22 \%)$ e o alívio de movimentos repetitivos (20\%). Como desvantagens eles apontam o medo de acidentes (30\%), o medo da mudança e do desconhecido (25\%) e o fato de se sentirem inseguros (18\%). Já os trabalhadores da 
área limpa definem como vantagens do rodízio o aprendizado e ganho de experiência gerados (40\%), o fato de proporcionar mudanças de movimentos (35\%) e a possibilidade de descanso físico (32\%). Como desvantagens eles colocam a insegurança gerada (12\%) e a possibilidade do rodízio gerar penosidade e aumento da dificuldade no trabalho (10\%).

\subsection{Aceitação da realização do rodízio em função do posto de trabalho}

Com relação aos postos de trabalho, na fase de análise das atividades foram selecionados oito postos (quatro para área limpa e quatro para área suja), identificados pelos trabalhadores como sendo os que apresentam risco elevado de acidentes e desenvolvimento de DORT. Esses postos exigem competências especificas e habilidade elevada com relação ao trabalho a ser executado em cada um deles. Na Figura 3 são apresentados a porcentagem aproximada e frequências mais citadas pelos trabalhadores $(n=79)$ em ocupar ou não cada posto e as barreiras e facilitadores (aspectos positivos e negativos) em ocupá-los. 


\begin{tabular}{|c|c|c|c|c|c|c|c|c|c|c|c|}
\hline \multirow[b]{2}{*}{ POSTO } & \multirow[b]{2}{*}{ 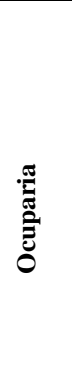 } & \multirow[b]{2}{*}{ 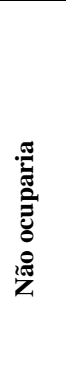 } & \multirow[b]{2}{*}{ 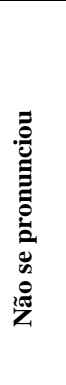 } & \multicolumn{4}{|c|}{ Aspectos positivos } & \multicolumn{4}{|c|}{ Aspectos negativos } \\
\hline & & & & 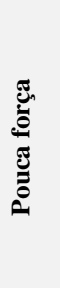 & 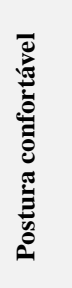 & 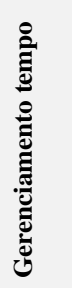 & 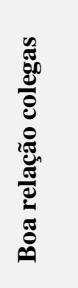 & 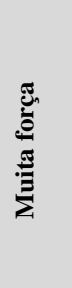 & 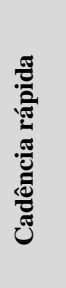 & 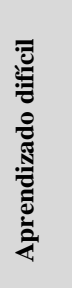 & 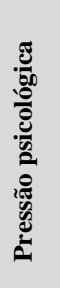 \\
\hline \multicolumn{12}{|c|}{ POSTOS ÁREA SUJA } \\
\hline Serra Peito & $\begin{array}{l}50 \% \\
(39) \\
\end{array}$ & $\begin{array}{l}44 \% \\
(35)\end{array}$ & $\begin{array}{l}6 \% \\
(5)\end{array}$ & $\begin{array}{l}20 \% \\
(16) \\
\end{array}$ & $\begin{array}{l}40 \% \\
(32) \\
\end{array}$ & $\begin{array}{l}80 \% \\
(63) \\
\end{array}$ & $\begin{array}{l}90 \% \\
(71) \\
\end{array}$ & $\begin{array}{l}70 \% \\
(55) \\
\end{array}$ & $\begin{array}{l}75 \% \\
(59)\end{array}$ & $\begin{array}{l}58 \% \\
(46) \\
\end{array}$ & $\begin{array}{l}60 \% \\
(47)\end{array}$ \\
\hline Tira couro & $\begin{array}{l}75 \% \\
(59) \\
\end{array}$ & $\begin{array}{l}20 \% \\
(16) \\
\end{array}$ & $\begin{array}{l}5 \% \\
(4)\end{array}$ & $\mathrm{NC}$ & $\begin{array}{l}45 \% \\
(35) \\
\end{array}$ & $\begin{array}{l}85 \% \\
(67) \\
\end{array}$ & $\begin{array}{l}90 \% \\
(71) \\
\end{array}$ & $\begin{array}{l}75 \% \\
(59) \\
\end{array}$ & $\begin{array}{l}85 \% \\
(67) \\
\end{array}$ & $\begin{array}{l}60 \% \\
(47) \\
\end{array}$ & $\begin{array}{l}70 \% \\
(55) \\
\end{array}$ \\
\hline $\begin{array}{l}\text { Etiqueta e } \\
\text { Transpasse }\end{array}$ & $\begin{array}{l}55 \% \\
(43)\end{array}$ & $\begin{array}{l}25 \% \\
(20)\end{array}$ & $\begin{array}{l}20 \% \\
(16)\end{array}$ & $\mathrm{NC}$ & $\begin{array}{l}60 \% \\
(47)\end{array}$ & $\begin{array}{l}70 \% \\
(55)\end{array}$ & $\begin{array}{l}95 \% \\
(75)\end{array}$ & $\begin{array}{l}70 \% \\
(55)\end{array}$ & $\begin{array}{l}90 \% \\
(71)\end{array}$ & $\begin{array}{l}40 \% \\
(32)\end{array}$ & $\begin{array}{l}45 \% \\
(35)\end{array}$ \\
\hline Sangria & $\begin{array}{l}60 \% \\
(47) \\
\end{array}$ & $\begin{array}{l}25 \% \\
(20) \\
\end{array}$ & $\begin{array}{l}15 \% \\
(12)\end{array}$ & NC & $\begin{array}{l}65 \% \\
(51) \\
\end{array}$ & $\begin{array}{l}75 \% \\
(59) \\
\end{array}$ & $\begin{array}{l}55 \% \\
(75) \\
\end{array}$ & $\begin{array}{l}80 \% \\
(63) \\
\end{array}$ & $\begin{array}{l}90 \% \\
(71) \\
\end{array}$ & $\begin{array}{l}55 \% \\
(35) \\
\end{array}$ & $\begin{array}{l}65 \% \\
(51) \\
\end{array}$ \\
\hline \multicolumn{12}{|c|}{ POSTOS ÁREA LIMPA } \\
\hline $\begin{array}{c}\text { Serra } \\
\text { carcaça }\end{array}$ & $\begin{array}{l}40 \% \\
(32)\end{array}$ & $\begin{array}{l}50 \% \\
(39)\end{array}$ & $\begin{array}{c}10 \% \\
(8)\end{array}$ & NC & $\begin{array}{l}45 \% \\
(35)\end{array}$ & $\begin{array}{l}60 \% \\
(47)\end{array}$ & $\begin{array}{l}90 \% \\
(71)\end{array}$ & $\begin{array}{l}75 \% \\
(59)\end{array}$ & $\begin{array}{l}70 \% \\
(55)\end{array}$ & $\begin{array}{l}55 \% \\
(43)\end{array}$ & $\begin{array}{l}65 \% \\
(51)\end{array}$ \\
\hline $\begin{array}{l}\text { Limpeza da } \\
\text { Bacia e do } \\
\text { Filé }\end{array}$ & $\begin{array}{l}60 \% \\
(47)\end{array}$ & $\begin{array}{l}25 \% \\
(20)\end{array}$ & $\begin{array}{l}15 \% \\
(12)\end{array}$ & NC & $\begin{array}{l}45 \% \\
(35)\end{array}$ & $\begin{array}{l}65 \% \\
(51)\end{array}$ & $\begin{array}{c}100 \% \\
(79)\end{array}$ & $\begin{array}{l}45 \% \\
(35)\end{array}$ & $\begin{array}{l}70 \% \\
(55)\end{array}$ & $\begin{array}{l}55 \% \\
(43)\end{array}$ & $\begin{array}{l}55 \% \\
(43)\end{array}$ \\
\hline $\begin{array}{c}\text { Retirada da } \\
\text { Barrigada }\end{array}$ & $\begin{array}{l}40 \% \\
(32)\end{array}$ & $\begin{array}{l}30 \% \\
(24)\end{array}$ & $\begin{array}{l}30 \% \\
(21)\end{array}$ & $\mathrm{NC}$ & $\begin{array}{l}45 \% \\
(35)\end{array}$ & $\begin{array}{l}70 \% \\
(55)\end{array}$ & $\begin{array}{l}90 \% \\
(71)\end{array}$ & $\begin{array}{l}55 \% \\
(43)\end{array}$ & $\begin{array}{l}60 \% \\
(47)\end{array}$ & $\begin{array}{l}55 \% \\
(43)\end{array}$ & $\begin{array}{l}70 \% \\
(55)\end{array}$ \\
\hline Carimbo & $\begin{array}{l}99 \% \\
(78)\end{array}$ & $\begin{array}{l}1 \% \\
(1)\end{array}$ & $\begin{array}{l}0 \% \\
(0)\end{array}$ & $\begin{array}{l}65 \% \\
(51)\end{array}$ & $\begin{array}{l}70 \% \\
(55)\end{array}$ & $\begin{array}{l}75 \% \\
(59)\end{array}$ & $\begin{array}{c}100 \% \\
(79)\end{array}$ & $\begin{array}{l}35 \% \\
(27)\end{array}$ & $\begin{array}{l}30 \% \\
(24)\end{array}$ & $\begin{array}{l}30 \% \\
(24)\end{array}$ & $\begin{array}{l}70 \% \\
(55)\end{array}$ \\
\hline
\end{tabular}

Figura 3 - Porcentagem aproximada e frequencia das manifestações de cada trabalhador (n=79) em ocupar ou não os postos selecionados na área suja e limpa e as barreiras e facilitadores em ocupá-los.

Legenda: NC - Não citadas.

Com relação aos aspectos positivos e negativos, 79 trabalhadores responderam acerca dos 8 postos de trabalho, o que significa uma possibilidade de 632 respostas para cada categoria, caso todos eles respondam as questões relativas a cada item de cada posto. De modo geral, os resultados mostram que as razões mais frequentemente citadas para ocupar os postos são: boa relação com colegas (592 citações) e gerenciamento do tempo (456 citações). Por outro lado, as razões mais evocadas para não ocupar os postos são: a força exercida (396 citações), cadência rápida (449 citações) e pressão psicológica (392 citações). 
Os postos de trabalho da área suja foram mais frequentemente considerados como necessitando de muita força e tendo uma cadência rápida, quando comparados aos da área limpa. O posto "Tira-Couro" foi o mais bem aceito da área suja, sendo que somente $25 \%$ dos trabalhadores responderam que não o ocupariam. Entre as razões mais citadas, encontram-se a boa relação com colegas e o gerenciamento do tempo, apesar da cadência elevada. O posto menos escolhido da área suja foi o do "Serra-Peito" (50\% dos trabalhadores), a maioria das respostas indica que o posto demanda muita força (citado 55), a cadência é rápida (citado 59), e a pressão psicológica é presente (citado 47). Com efeito, trata-se de um posto que necessita do uso de serra elétrica que nem sempre apresenta boas condições de corte devido à falta de manutenção, exigindo mais força dos trabalhadores.

$\mathrm{Na}$ área limpa, $100 \%$ dos entrevistados concordam em ocupar o posto de carimbo. Apesar de ser considerado um posto de elevada pressão psicológica ${ }^{2}$, este também é um posto apresentando mais aspectos positivos (boa relação com colegas, gerenciamento do tempo, postura confortável, pouca força e fácil aprendizado) e menos aspectos negativos. O posto de "Serra-Carcaça" foi rejeitado por $50 \%$ dos trabalhadores. Dentre as razões, foram mais frequentemente citadas a força exercida (manuseio de serra pneumática sobre plataforma, citado 59 vezes) e a pressão psicológica.

\subsection{A prática informal do rodízio de postos: percepção dos trabalhadores}

\section{envolvidos}

\subsubsection{Alternância do uso de serra e de plataforma}

Os postos que exigem a utilização de serra (elétrica e pneumática) foram os menos aceitos pelos trabalhadores para ocupação no caso de rodízio. No entanto, foi observado que um rodízio informal acontecia entre o posto de serra carcaça (trabalhador T1, 45 anos, 4,5 anos de experiência) e o posto de retirada da cabeça do animal (trabalhador T2, 39 anos, 2 meses de experiência). Considerando o aspecto penoso de cada posto, os trabalhadores envolvidos decidiram pedir ao encarregado a autorização

\footnotetext{
${ }^{2}$ Pela presença do pecuarista que vende a boiada para a empresa e vigia a boiada próximo aos postos de limpeza do filé, carimbo do lote e balança. Sua presença visa teoricamente a monitoria da boiada para verificação de doenças ou irregularidades, mas também o controle do peso final das carcaças e, consequentemente, do preço total do lote. Uma trabalhadora do carimbo indica que "dependendo da marcação, é determinado o preço - é o preço que eles recebem aqui. Quando está machucado eu tenho que marcar, e o preço da arroba do boi diminui".
} 
para alternar as atividades. A demanda foi aceita e os trabalhadores tinham autonomia para organizar as trocas, sem que houvesse um tempo dedicado ao treinamento nem aos critérios do rodízio (tempo, frequência, duração, etc.). O rodízio entre os dois tipos de postos corresponde às exigências da NR-36, no sentido em que há alternância do trabalho com e sem plataformas, e com e sem serras pneumáticas, pois o trabalho do posto de serra carcaça é realizado em plataforma, enquanto o posto de retirada da cabeça do animal se realiza sem plataforma. Os trabalhadores se organizaram para realizar a troca em momentos favoráveis para ambos. A estratégia adotada foi implementar a troca com base em um determinado número de animais a serem trabalhados, mas também levando em conta o fator coletivo e a organização do trabalho em linha de produção: "Preferimos trocar a cada 250 bois ou mais, em vez de trocar a cada hora. Pra evitar parar a linha, também fazemos as mudanças quando a linha está parada" (T1). Ambos concordam e preferem não trocar de posto em um momento prédefinido para não interromper a produção nem correr o risco de causar atrasos. Porém, a regra do número alvo de bois (250 por exemplo), nem sempre pode ser respeitada se não associada a parada da linha de produção, que pode acontecer por razões diversas (falta de manutenção, queda de eletricidade, atrasos no processo de produção, etc.). Por conta disto, os trabalhadores regulam em função do trabalho real e suas variabilidades, o que conduz a uma segunda configuração das trocas: cada um ocupa seu posto de origem e a troca é realizada após o intervalo do almoço, independentemente do número de bois abatidos antes do intervalo. "Às vezes a gente troca depois do almoço, independentemente do número de bois que fizemos pela manhã’" (T2).

A rotação foi vista como um elemento positivo pela dupla, dando-lhes a possibilidade de variar suas atividades e, portanto, os constrangimentos do trabalho. "É menos cansativo, também menos estressante, porque você muda de um posto para outro. Vou dizer aos meus colegas para também praticarem a rotação mudando de postos, porque, se todos mudarem, no final, todos terão descansado pelo menos um pouquinho. (T1)". Nota-se que a rotação é vista como a possibilidade de "descanso" relativamente ao posto ocupado, embora esse descanso não seja efetivo pois o trabalhador continua exercendo a atividade na linha de produção, em outro posto.

3.4.2 Alternância de constrangimentos do trabalho relacionados ao espaço e ao número dos gestos repetitivos 
A limpeza do filé mignon (trabalhadora T3, 54 anos, 15 anos de experiência) e a limpeza da bacia da meia-carcaça (trabalhador T4, 45 anos, 11 anos de experiência) são realizadas por dois trabalhadores que se encontram lado a lado na linha de produção, trabalhando na mesma plataforma. Foi observado que um rodízio informal acontecia entre os dois postos, que apresentam constrangimentos, portanto, similares. As exigências biomecânicas mais visíveis estão nos membros superiores (6 a 8 facadas por meia carcaça com os braços à altura do ombro), sendo movimentos precisos e rítmicos, requerendo uma sintonia obrigatória entre os trabalhadores e as máquinas. Observamos um ritmo de 3 a 4 carcaças por minuto. Com este ritmo, os trabalhadores dizem que não têm tempo para seguir a regra de higiene de lavar a faca entre cada carcaça, tão pouco conseguem afiar a faca regularmente. Eles devem acompanhar o ritmo constante (mas nem sempre regular devido às paradas de linha por falta de energia ou recuperação de erros) ao mesmo tempo que respeitam as regras de higiene e de qualidade do produto. Essas exigências face à velocidade acelerada da nória conduzem a arbitragens: esterilizar, trocar e amolar a faca quando dá. "Por que na verdade isso é exigido pelo controle de qualidade e pelo gerente, só que para cumprir isso é complicado, a não ser quando tem auditoria e a velocidade da nória está a 90/h, suave. Aí se tem tempo de fazer, troca normal, mas na velocidade de 120/h não dá. "(T4).

Apesar dos constrangimentos parecerem similares em uma primeira observação, a partir das análises da atividade realizada nos dois postos, entendemos que a trabalhadora T3 é submetida a um constrangimento de espaço-tempo diferente do colega pois a limpeza do filé mignon demanda mais gestos do que a limpeza da bacia. A crônica de atividade apresentado na Figura 04, com base em 4’20" de observação da atividade da trabalhadora T3, ilustra os ditos constrangimentos e seus efeitos nas ações realizadas pela trabalhadora. 


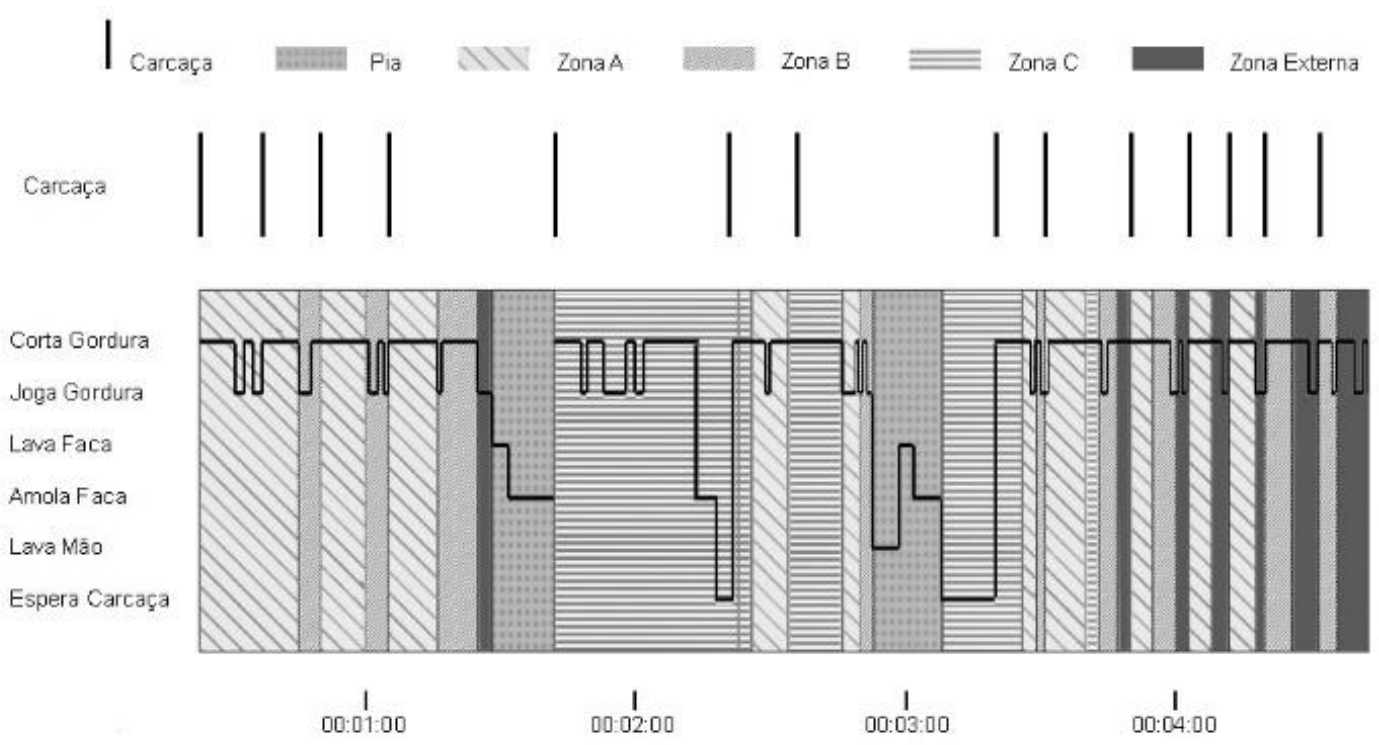

Legenda: Zona A: Área da plataforma onde T3 alcança as carcaças para limpeza.

Zona B: Área da plataforma onde T3 alcança as carcaças com pequenos deslocamentos.

Zona C: área da plataforma que $\mathrm{T} 3$ se antecipa a chegada da carcaça para início limpeza.

Zona Externa: Área da plataforma onde T3 se desloca, ficando inclinada na barreira de proteção do corpo, para conseguir finalizar o trabalho de limpeza da carcaça.

Figura 4: Crônica de ações realizadas pela trabalhadora T3 no posto de limpeza do filé mignon a partir do software Actograph. Nas ordenadas, as açoes observadas; nas abcissas, o tempo em minutos.

Durante um período de menos 5 minutos, a trabalhadora limpou 14 carcaças, lavou sua faca duas vezes e também a afiou duas vezes (área da pia). Ela se permite fazer isto quando tem tempo suficiente entre 2 carcaças (4 e 5, e 7 e 8). Neste momento, antecipa e ocupa uma zona $\mathrm{C}$, no montante da linha de produção.

Deve-se observar que quando o ritmo da cadeia é regular (primeiras 4 carcaças), a trabalhadora permanece nas zonas onde a carcaça é alcançada (A e B). Isto não é mais possível quando as carcaças estão muito próximas umas das outras (a partir de 10). Nesse caso, a trabalhadora sai do espaço do seu posto (áreas A, B e C) em direção a uma "zona externa", tendo que se inclinar para frente contra a barra de proteção para finalizar a limpeza. Ela se "atrasa" para a próxima meia-carcaça e, tentando recuperar o atraso, encontra-se novamente em "zona externa" ao posto.

Considerando os constrangimentos do posto, os trabalhadores T3 e T4 entraram em um acordo informal quanto às trocas. Para cada 100 bois, mudam de lugar (e, portanto, de função), a fim de reduzir a exposição de T3 à restrição de espaço-tempo durante o "os atrasos" induzidos pela concentração rápida de carcaças em cadência 
elevada. A proposta foi feita por T3 e aceita pelo encarregado e pelo colega T4, encarregado da limpeza da parte externa da carcaça (bacia), considerada menos difícil e menos cansativa. Nota-se que, como no exemplo anterior, o rodízio acontece de maneira informal e sem preparação prévia dos gestores em termos de organização eficaz levando em conta a saúde, a segurança e a produtividade.

\section{Discussão}

Ao realizar uma revisão de literatura acerca das atividades de trabalho em indústrias frigoríficas, Ferreira et al. ${ }^{20}$ identificam que praticamente todas elas têm relação com sobrecargas musculo-esqueléticas dos trabalhadores. Apesar disso, poucos são os estudos que buscam aprofundar a análise de possíveis alternativas de prevenção das sobrecargas reconhecidamente sofridas pelos trabalhadores ou mesmo na compreensão da percepção dos mesmos quando da implantação dessas alternativas, como rodízio dos postos de trabalho.

Nesse sentido, a percepção dos trabalhadores no processo de implantação do rodízio teve lugar central nesta pesquisa, dado que ela possibilitou identificar suas vantagens e desvantagens, na perspectiva dos trabalhadores. Foi possível perceber, por exemplo, que a boa relação com colegas e a gestão do tempo estão entre os critérios utilizados para ocupar os postos de trabalho, enquanto a força exercida, a alta cadência e a sensação de pressão psicológica estão entre as principais razões para não ocupá-los. Dessa maneira, postos como "Serra-Peito" e "Serra-Carcaça" foram os mais rejeitados, com metade dos trabalhadores se recusando a ocupá-los.

Se os estudos são escassos no que concerne à compreensão da percepção dos trabalhadores no processo de implantação de rodízios, ainda mais raros são aqueles que valorizam a participação dos sujeitos na construção do rodízio. Esse cenário se reproduz apesar das exigências da própria NR-36 ${ }^{6}$, que enfatiza a necessidade dessa participação: na avaliação do rodízio, de acordo com a aceitação dos trabalhadores (item 36.14.7.3); na escolha das ferramentas (item 36.8.10); na avaliação, controle e monitoramento dos riscos (item 36.11.5); bem como nos treinamentos (item 36.16.5).

A presente pesquisa traz elementos bastante pragmáticos em relação à necessidade de participação dos indivíduos no processo. Isso pôde ser observado já na consulta inicial de aceitação de participação no rodízio. Como mostrado, se inicialmente $72 \%$ 
dos entrevistados não estavam dispostos a participar do rodízio, após a integração dos mesmos no processo, $86 \%$ dos trabalhadores da área suja e 64\% da área limpa mudaram de opinião e aceitaram participar. Além disso, é interessante perceber as diferentes formas de rodízios informais nascidos entre os próprios trabalhadores, com dinâmicas próprias de funcionamento inerentes à cada grupo. Essas práticas informais só são efetivas devido à autonomia e ao grau de participação que os próprios trabalhadores têm no processo. Neste sentido, eles criam iniciativas, afirmando que preferem "trocar a cada 250 bois ou mais", que trocam após o almoço "independentemente do número de bois que fizemos pela manhã" ou mesmo o número de participantes envolvidos pois, assim, no final "todos terão descansado pelo menos um pouquinho".

A implantação de rodízio é sempre uma questão complexa, que deve ser abordada como um projeto sistêmico na empresa. Por um lado, é necessário um profundo conhecimento das atividades desenvolvidas pelos indivíduos, para que mudanças organizacionais sejam propostas. Como advogam Vilela et al. ${ }^{15}$, se as intervenções referenciadas somente nas normas em saúde e segurança do trabalho exibem os riscos visíveis, aquelas que se servem da ergonomia da atividade são capazes de identificar causas muito mais profundas, relacionadas aos aspectos organizacionais. Por outro lado, é necessário que o trabalhador ocupe um lugar central no processo de concepção do rodízio, do qual o mesmo fará parte, e que a gestão se comprometa a oferecer condições de realização do mesmo. É sob esse ângulo que Coutarel et al. ${ }^{11}$ estabelecem algumas dessas condições, tais como a participação dos operadores e o ganho de margem de manobra dos mesmos, através do ganho de espaços na cadeia produtiva, a adaptação do material utilizado (facas, afiadores, etc.) e o desenvolvimento das competências dos participantes.

Essas condições, ou a ausência delas, podem explicar porque $72 \%$ dos trabalhadores eram inicialmente contrários à participação no rodízio. Como mostram os resultados, daqueles contrários, a incerteza de treinamento adequado para o desenvolvimento das habilidades e o receio de exposição mais frequente a acidentes ocuparam, respectivamente, $35 \%$ e $30 \%$ do grupo. Observou-se que iniciativas realizadas por grupos isolados de trabalhadores não são plenamente eficientes, por não considerarem a intervenção de forma sistemática e global. Além disso, observamos que a autonomia para realizar a "troca" informal, não elimina os constrangimentos no espaço de trabalho e repetições de movimentos. Na crônica da atividade (ver Figura 4), a trabalhadora T3 ocupa "zona externa" à sua área de trabalho para finalizar ou refinar a 
limpeza do filet mignon. Neste caso, a ferramenta adequada de trabalho (a faca) e o tempo para realizar sua manutenção, no caso afiação, deveriam ser adequados à cadência e ao ritmo impostos pela noria. Questões como treinamento adequado, troca de experiências na realização da atividade, diminuição da cadência, são diretrizes que devem ser consideradas em conjunto ${ }^{11}$, e não com atitudes isoladas dos trabalhadores.

Em revisão de literatura sobre a eficácia de intervenções ergonômicas participativas $^{21}$, poucos são os estudos com metodologia robusta. Os casos que apresentam experiências da intervenção participativa na implementação de normas regulatórias são ainda mais escassos. No Brasil, talvez por questões culturais, os trabalhadores em qualquer posição são pouco ouvidos em questões de implementação de desenhos organizacionais, sendo que, quando se considera trabalhadores operacionais, essa questão é quase inexistente.

O resultado da presente pesquisa mostra que a abordagem participativa preliminar às mudanças de desenhos organizacionais contribui para a compreensão e percepção pelo trabalhador, das reais vantagens e desvantagens nas implantações das exigências legais. A compreensão dos fatores aqui levantados, tanto as barreiras como os facilitadores, na implementação do rodízio de postos, podem ser estendidos a outros trabalhadores do setor de abate de bovinos. De fato, pode-se concluir que a abordagem participativa preliminar às implementações legais e organizacionais resgatam o protagonismo interno do trabalhador, favorecendo sua vocalidade dentro do processo. Entretanto, devem sempre ser considerados o contexto e o objeto de cada intervenção, pois não existe padronização das ações ${ }^{19}$. A organização tem que dar as condições para que a implantação aconteça de acordo os critérios recomendados em outros estudos ${ }^{11}$, 17, 18, 21 . A construção da participação nos desenhos organizacionais está relacionada a melhorias das condições dos ambientes e ambiências de trabalho. Portanto, realizar a abordagem colocando o trabalhador no centro do projeto de concepção pode ser considerada condição fundamental para o sucesso de intervenções ergonômicas na implantação de normas regulatórias. A legislação, apesar de prescrever a participação efetiva do trabalhador, não apresenta as alternativas de como essas podem, de fato, ocorrer. Esse trabalho descreve a experiência de um processo participativo não comum a gestão organizacional no Brasil. Efetivamente, mudanças organizacionais que ocorrem com a participação do protagonista da ação ${ }^{22}$, aproxima o prescrito, no caso a 
implantação de exigências legais, ao real, fortalecendo o coletivo do trabalho e a melhoria de suas condições, como a redução das DORT's.

\section{Agradecimento}

Os autores agradecem a Fundação de Amparo a Pesquisa no Estado de São Paulo - FAPESP pelo suporte na concessão de recursos dentro da modalidade de Auxílio à Pesquisa Regular.

\section{Financiamento}

Este estudo foi financiado pela Fundação de Amparo a Pesquisa no Estado de São Paulo - FAPESP Processo número 2017/05299-5.

\section{Contribuição dos autores}

IA Messias contribuiu na concepção e delineamento do estudo, interpretação e análise dos dados, elaboração e revisão do manuscrito; A Nascimento contribuiu na concepção, análise e interpretação dos dados, elaboração do artigo e revisão do manuscrito; e R Rocha contribuiu na interpretação dos dados, na redação do artigo e sua revisão. Informo também que, todos os autores revisaram criticamente o manuscrito sobre a importância do seu conteúdo intelectual e fizeram aprovação da versão final.

\section{Conflitos de interesses}

Não há qualquer conflito de interesses dos autores em relação a este manuscrito.

\section{Referências bibliográficas}

1. Molinié AF, Volkoff S. La Charge de Travail. Statistiques Du Travail, Supplément No.84.; 1980.

2. Falardeau A, Vezina N. Apport de différentes sources de données à la description comparée des contraintes et à l'amélioration d'un groupe de postes occupés en rotationContribution of different sources of data to the compared description of 
constraints and to the improvement of. Perspect Interdiscip sur le Trav la santé. 2004;(6-1):0-27. doi:10.4000/pistes.3282

3. Sormunen E, Oksa J, Pienimäki T, Rissanen S, Rintamäki H. Muscular and cold strain of female workers in meatpacking work. Int J Ind Ergon. 2006;36(8):713-720. doi:10.1016/j.ergon.2006.05.003

4. Sundstrup E, Jakobsen MD, Andersen $\mathrm{CH}$, et al. Participatory ergonomic intervention versus strength training on chronic pain and work disability in slaughterhouse workers: Study protocol for a single-blind, randomized controlled trial. BMC Musculoskelet Disord. 2013;14. doi:10.1186/1471-2474-14-67

5. Vogel K, Karltun J, Eklund J, Engkvist IL. Improving meat cutters' work: Changes and effects following an intervention. Appl Ergon. 2013;44(6):996-1003. doi:10.1016/j.apergo.2013.03.016

6. Brasil. Portaria MTE n. ${ }^{\circ}$ 555, de 18 de abril de 2013 D.O.U. Nr-36 - Segurança e Saúde no trabalho em empresas de abate e processamento de carnes e derivados. Diário Of da União. 2013;(36):20.

7. Oliviera PAB, Mendes JMR. Processo de trabalho e condições de trabalho em frigoríficos de aves: Relato de uma experiência de vigilância em saúde do trabalhador. Cienc e Saude Coletiva. 2014;19(12):4627-4635. doi:10.1590/1413812320141912.12792014

8. Marra GC, Souza LH de, Cardoso TA de O. Biossegurança no trabalho em frigoríficos: da margem do lucro à margem da segurança. Cien Saude Colet. 2013;18(11):32593271. doi:10.1590/s1413-81232013001100016

9. Ouellet S, Vézina N. L'implantation de la rotation de postes : un exemple de démarche préalable. Perspect Interdiscip sur le Trav la santé. 2003;(5-2):0-30. doi:10.4000/pistes.3322

10. Barth DC, LBM G. Análise do impacto do rodízio no grau de risco postural e de desconforto/dor de trabalhadores na desossa de frango. In: Associação, Brasileira de Ergonomia - ABERGO, eds. Anais Do 14o Congresso Brasileiro de Ergonomia. Porto Seguro; 2008.

11. Coutarel, F.; Daniellou, F., Dugué B. Interroger l'organisation du travail au regard des marges de manœuvre en conception et en fonctionnement. La rotation est-elle une 
solution aux TMS ? Perspect Interdiscip sur le Trav la santé - Pist. 2003;2:1-21.

12. $\mathrm{C} \mathrm{C}, \mathrm{N} \mathrm{V}, \mathrm{J}$ P. Formation et soutien à l'apprentissage: des conditions indispensables à la polyvalence et à la santé et sécurité au travail. PISTES. 2003;5:1-26.

13. Neiva S, Silva I. Vantagens e desvantagens da rotação de postos de trabalho: a visão dos trabalhadores e das chefias. In: Araújo M, Martins D, D O, eds. Investigação e Intervenção Em Recursos Humanos - Gestão Para a Cidadania. Porto: Instituto Politécnico do Porto/ Edições Politema; 2012:597-608.

14. Padula RS, Luiza M, Comper C, Sparer EH, Dennerlein JT. Job rotation designed to prevent musculoskeletal disorders and control risk in manufacturing industries: A systematic review. Appl Ergon. 2017;58:386-397. doi:10.1016/j.apergo.2016.07.018

15. Vilela, Rodolfo Andrade de Gouveia, almeida, Ildeberto Muniz, Mendes RW. Da vigilância para prevenção de acidentes de trabalho: contribuição da ergonomia da atividade From surveillance to work-related accident prevention : the contribution of the ergonomics of the activity. Cien Saude Colet. 2012:2817-2830.

16. Burgess-limerick R. Participatory ergonomics : Evidence and implementation lessons. Appl Ergon. 2018;68(3):289-293. doi:10.1016/j.apergo.2015.05.004

17. Nascimento A, Messias I de A. Job rotation in beef packing operations: Beyond the physical dimensions of work. Cad Saude Publica. 2018;34(10):1-11. doi:10.1590/0102-311x00095817

18. Wilson JR. Ergonomics and participation. In: Wilson JR, Corlett EN, eds. Evaluation of Human Work. Taylor and. London: second ed.; 1995.

19. Van Eerd D, Cole D, Irvin E, et al. Process and implementation of participatory ergonomic interventions: a systematic review. Ergonomics. 2010;53:1153-1166.

20. Ferreira E, Andrés E, Merino D, Garcia L, Vergara L, Gontijo LA. Estado da arte em frigoríficos: a influência de fatores ergonômicos sobre o desempenho. In: Fourth International Conference on Integration of Design, Engineering and Management for $\begin{array}{llll}\text { Innovation. } & \text { Florianóplis } & \text { /SC: } & \text { 2015, }\end{array}$ https://www.researchgate.net/publication/306375190.

21. Rivilis I, Van Eerd D, Cullen K, et al. Effectiveness of participatory ergonomic interventions on health outcomes: A systematic review. Appl Ergon. 2008;39(3):342358. doi:10.1016/j.apergo.2007.08.006 
22. Sznelwar L. Quando Trabalhar É Ser Protagonista e o Protagonismo No Trabalho. Editora Edgard Blücher; 2015. 